\title{
DIAGNÓSTICO SÓCIO-ECONÔMICO E TECNOLÓGICO DO SETOR AGRÍCOLA EM ALGUNS MUNICÍPIOS DA REGIÃO DO CARIRI CEARENSE
}

\author{
A. G. S. Feitosa', C. A. Marco ${ }^{2}$, H. R. Santos ${ }^{3}$, C. S. Silva ${ }^{4}$ e J. V. Feitosa ${ }^{5}$ \\ Universidade Federal do Ceará \\ clmarko@ufc.bre glaydson_feitosa@yahoo.com.br
}

Artigo submetido em novembro/2011 e aceito em março/2012

\section{RESUMO}

Esta pesquisa teve como objetivo caracterizar os municípios de Crato, Barbalha e Missão Velha no que se refere à atividade agrícola. Com o auxílio de formulário, socioeconômico, tecnológico e de informações fornecidas pela Empresa de Assistência Técnica e Extensão Rural do Ceará (EMATERCE), foi realizada uma pesquisa amostral em 169 propriedades rurais de pequeno e médio porte, classificadas em três grupos, agricultura de subsistência + fruticultura, subsistência e hortaliças. $\mathrm{O}$ grupo que teve como atividades principais a agricultura de subsistência + fruticultura correspondeu a $42 \%$ do total e apresentou um predomínio de consórcio entre milho e feijão ou milho e fava, já quanto às frutíferas observou-se um predomínio de banana e goiaba.As condições de vida são consideradas boas porém ainda há pouca utilização de tecnologia na agricultura. A maioria dos produtores comercializa seus produtos, mas recomenda-se um maior incentivo dos órgãos competentes, através de assistência técnica, cursos sobre gerenciamento agrícola e organização de produtores e maiores subsídios para melhoria da agricultura praticada nessas propriedades.

PALAVRAS-CHAVE:Formulário; Subsistência; Agricultura.

\section{DIAGNOSTIC SOCIO-ECONOMIC AND TECHNOLOGY IN THE AGRICULTURAL SECTOR IN SOME MUNICIPALITIES OF THE REGION CARIRI CEARENSE}

\begin{abstract}
The objective of this research was to characterize the municipalities of Crato, Barbalha and Missão Velha regard to agricultural activity. With the aid of form, economic, technological and information provided by EMATERCE, Rural Workers Union of Municipalities and the Office Agropole of Ceará, a search was conducted in 169 sample farms, small and medium businesses, classified according to what farm, agriculture and fruit production for subsistence, livelihood and vegetables. The group that had the main activities to subsistence farming and fruit production was $42 \%$ and showed a
\end{abstract}

predominance of consortium between corn and beans or corn and beans. As the fruit there was a predominance of banana and guava. The Living conditions are considered good, but there is little use of technology in agriculture. Most farmers markets its products, but it is recommended a greater incentive of competent bodies, through technical assistance, courses about agricultural management and producer organization and greater benefits for the improvement of agriculture practiced in these properties.

KEY-WORDS: formulary, subsistence, agriculture. 


\section{DIAGNÓSTICO SÓCIO-ECONÔMICO E TECNOLÓGICO DO SETOR AGRÍCOLA EM ALGUNS MUNICÍPIOS DA REGIÃO DO CARIRI CEARENSE}

\section{INTRODUÇÃO}

Nas pequenas e médias cidades brasileiras, a ausência de informações básicas sobre o setor rural dificulta a realização de qualquer diagnóstico da situação sócio-econômica e de um planejamento conseqüente para os municípios que visam implementar processos de desenvolvimento rural. Esta deficiência de informação pode estimular o desenvolvimento de políticas públicas mal formuladas que são avaliadas com base em parâmetros técnicos não confiáveis que desperdiçam recursos públicos (OTANI et al., 2002).

A região do Cariri cearense, formada por trinta e três municípios encravados ao longo da fronteira com Pernambuco até os limites do Piauí e da Paraíba pelo prolongamento da Chapada do Araripe, é insuficiente de estudos nesse sentido. Dentre esses vários municípios, tem-se Crato, Barbalha e Missão Velha.

O município do Crato é conhecido por muitos como o "Oásis do Sertão", no extremo sul do Estado do Ceará, sendo a segunda cidade mais importante do Cariri em termos econômicos.

Barbalha está localizada na região, junto com as cidades do Crato e Juazeiro do Norte ficando a $503 \mathrm{~km}$ da capital cearense, Fortaleza; apresentando um desenvolvimento agrícola com enfase, principalmente, no cultivo de fruteiras e hortaliças, contribuindo para o desenvolvilmento econômico e sustentável da região (OLIVEIRA et al., 1999).

Já o município de Missão Velha, dedica-se produção de algodão arboreo e herbaceo, cana-de-açucar, milho e feijão, sendo considerado o segundo maior produtor de milho da região do Cariri. Devido a importância destas cidades para a região, os resultados desta pesquisa são considerados relevantes, pois fornecem subsídios adicionais para que as comunidades, a pesquisa e o poder público possam avaliar as formas de implementação do desenvolvimento local, traçando programas e projetos direcionados ao potencial agrícola de cada região.

Diante disso, o presente trabalho teve como objetivo traçar um diagnóstico sócio-econômico e tecnológico do setor agrícola nos três municípios do Cariri Cearense citados com vistas a fornecer uma base de dados que oriente o planejamento da agricultura na região e contribuindo para o desenvolvimento sustentável do meio rural da região sul cearense.

\section{MATERIAL E MÉTODOS}

A amostragem de investigação foi representado por propriedades rurais de pequeno e médio porte localizadas nos municípios de Crato, Barbalha e Missão Velha, todos pertencentes à região do Cariri cearence.

Em função do número expressivo de propriedades agrícolas existentes na região, não foi possível realizar uma pesquisa do tipo censitária, sendo esta do tipo amostral, com amostras definidas com o auxílio de informações fornecidas pelo escritório da Empresa de Assistência Técnica e Extensão Rural (EMATERCE Cariri), do Instituto Agropolos do Ceará (AGROPOLOS) e dos Sindicatos dos Trabalhadores Rurais de cada município, sendo que o critério utilizado para 
identificar a população foi o tamanho da propriedade rural, que não poderia exceder 10 ha. Do total foram sorteadas 169 propriedades que representaram a amostra trabalhada.

Devido à heterogeneidade de cultivos presentes nessa amostra resolveu-se classificar em grupos as propriedades existentes em cada município. Os grupos foram formados de acordo com aptidão agrícola: $\mathrm{A}, \mathrm{B}$ e/ou $\mathrm{C}$. O grupo $\mathrm{A}$ tem como aptidão agrícola a agricultura de subsistência (milho, feijão, fava, soja, mandioca, macaxeira, arroz e andu) e fruticultura (banana, goiaba, ciriguela, caju, etc.) , o grupo B cultiva somente produtos da agricultura de subsistência (milho, feijão, fava, soja, mandioca, macaxeira, arroz e andu) e o grupo C cultiva hortaliças (alface, coentro, pimentão).

Após a seleção das propriedades, foi feito um cronograma anual de visitas, assim como um formulário socioeconômico e tecnológico contendo itens quantitativos e qualitativos a ser respondido pelo agricultor, durante as visitas técnicas, que ocorreram de outubro de 2007 a maio de 2008.

O primeiro município a ser visitado foi o de Crato, outubro de 2007 a janeiro de 2008, seguido por Barbalha, segunda quinzena de janeiro a março de 2008 e Missão Velha, segunda quinzena de março a maio de 2008.

\section{RESULTADOS E DISCUSSÃO}

Na ausência de registro no Censo Agropecuário/2006 do número de propriedades com área inferior a 10 ha convencionou-se selecionar as propriedades em cada município a partir de informações coletadas pela EMATER. No município do Crato, a amostra foi representada por sessenta e duas propriedades caracterizadas em dois grupos (A, B), além de quatro assentamentos rurais:10 de Abril, Malhada, Alegre Fruta e Jenipapo com 46, 11, 8 e 12 famílias assentadas, respectivamente.

O grupo A correspondeu a $63 \%$ das propriedades avaliadas. A atividade agrícola básica é de agricultura de subsistência (milho, feijão, fava, arroz e amendoim) e fruticultura (banana, goiaba, ciriguela, caju etc). Os consórcios do milho com a fava e milho com feijão destacaramse com $17 \%$ e $20 \%$ da área total cultivada, respectivamente, e sendo avaliados com as culturas de subsistência restantes, estes percentuais aumentaram para 37,9\% e 43,2\% na mesma ordem (Figura 1). No que se refere às fruteiras (Figura 1), em torno de $29 \%$ da área total, foi cultivada com a cultura da banana. Esta cultura tem grande relevância no Brasil, sendo o segundo maior produtor e consumidor mundial dessa fruta, ficando atrás apenas da Índia (MOREIRA, 1999). 


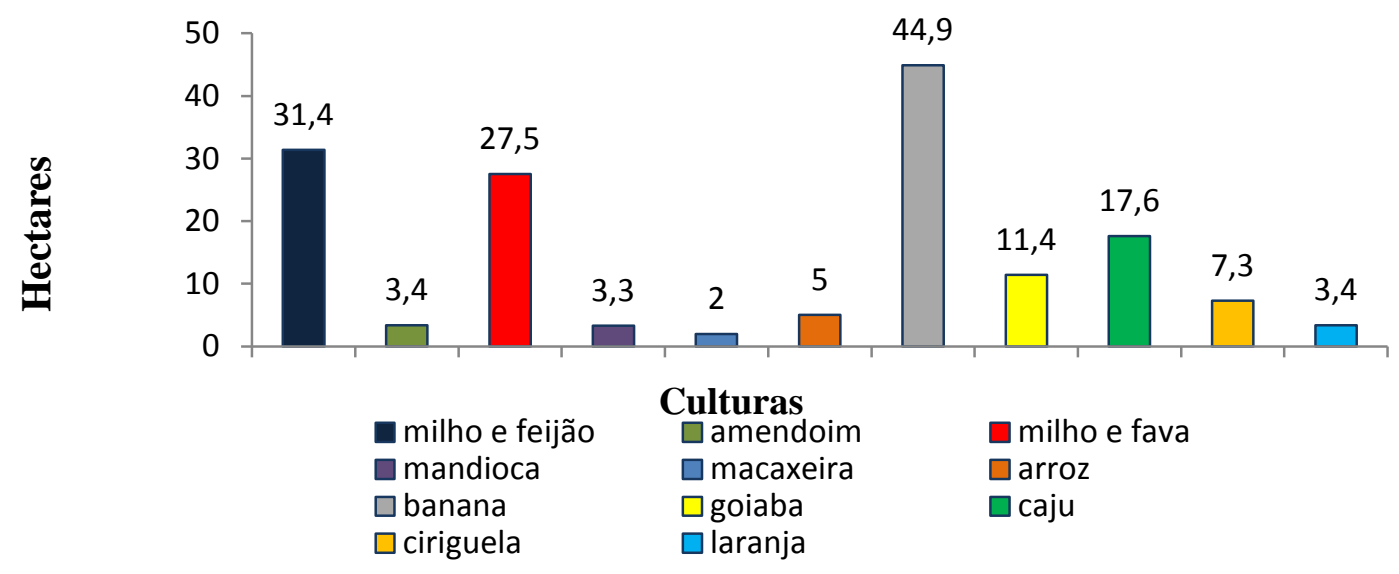

Figura 1. Cultivo de subsistência e Fruticultura (ha) presentes no grupo A. Crato-CE.

Estes dados confirmam com Nunes et al., (2006) que citam que o cultivo do milho em consórcio vem sendo bastante utilizado pelo agricultor nordestino por contribuir tanto na sua alimentação quanto na renda da família, além de amenizar os problemas relacionados às irregularidades climáticas, ficando menos exposto às perdas totais de produção. Entende-se por consorciação de culturas, o cultivo de duas ou mais espécies com diferentes ciclos e arquiteturas vegetativas, exploradas concomitantemente na mesma área e num mesmo período de tempo, sendo que não necessariamente tenham sido semeadas ao mesmo tempo (REZENDE et al., 2002b).

O sistema consorciado é empregado, sobretudo, pelos pequenos agricultores, que dessa forma, procuram aproveitar ao máximo as áreas limitadas de que dispõem, dos insumos e da mão-de-obra utilizada em capinas, adubações, aplicações de defensivos e outros tratos culturais Caetano et al., (1999), além de possibilitar maior diversificação da dieta e aumento da rentabilidade por unidade de área cultivada (COELHO et al., 2000). Em sistemas consorciados se estabelece um inter-relacionamento entre as culturas, do qual, poderá resultar uma inibição mútua quando o rendimento das culturas for inferior à expectativa, cooperação mútua quando o rendimento das culturas superar a expectativa ou compensação quando, diante da expectativa, uma cultura que produz menos é compensada por outra que produz mais do que a expectativa (WILLEY, 1979).

De modo geral, esse sistema não está associado com o uso de alta tecnologia, nem com a obtenção de altas produtividades (VIEIRA, 1989). Além disso, a bananeira, por ser uma planta tipicamente tropical, encontra condições climáticas favoráveis ao seu cultivo em quase todo o Brasil, com destaque para a região Nordeste Alves, (1999), constituindo parte importante da renda dos pequenos produtores e da alimentação das camadas mais carentes da população (MELO et al., 2006).

Em relação ao padrão de vida familiar, verifica-se que a maioria das famílias (próximo a $70 \%$ ), reside em casas de alvenaria e com banheiro, energia e água encanada (Figura 2). Esse resultado, provavelmente, deve-se ao incremento de renda que é obtido quando o produtor apresenta diversidade de cultivos (agricultura de subsistência e fruticultura) que permitem 
uma maior regularidade de produção ao longo do ano. Estes resultados estão de acordo ao citado por LIMA et al. (2005), quando comenta que a necessidade de cultivar duas ou mais culturas na mesma área leva o pequeno produtor a buscar melhores combinações de cultivo, a fim de diversificar a sua produção e obter outras fontes de alimento e renda. A eficiência e as vantagens de um sistema consorciado fundamentam-se, principalmente, na complementaridade entre as culturas envolvidas, sendo que esta será tanto maior, à medida que se consegue minimizar os efeitos negativos estabelecidos de uma cultura sobre a outra (CERETTA, 1986). Concordando com LIMA et al. (2005) e ALTIERI (2001), a grande diversidade de espécies desenvolvidas em policultivos, também ajuda na prevenção de pragas evitando sua proliferação entre indivíduos da mesma espécie.

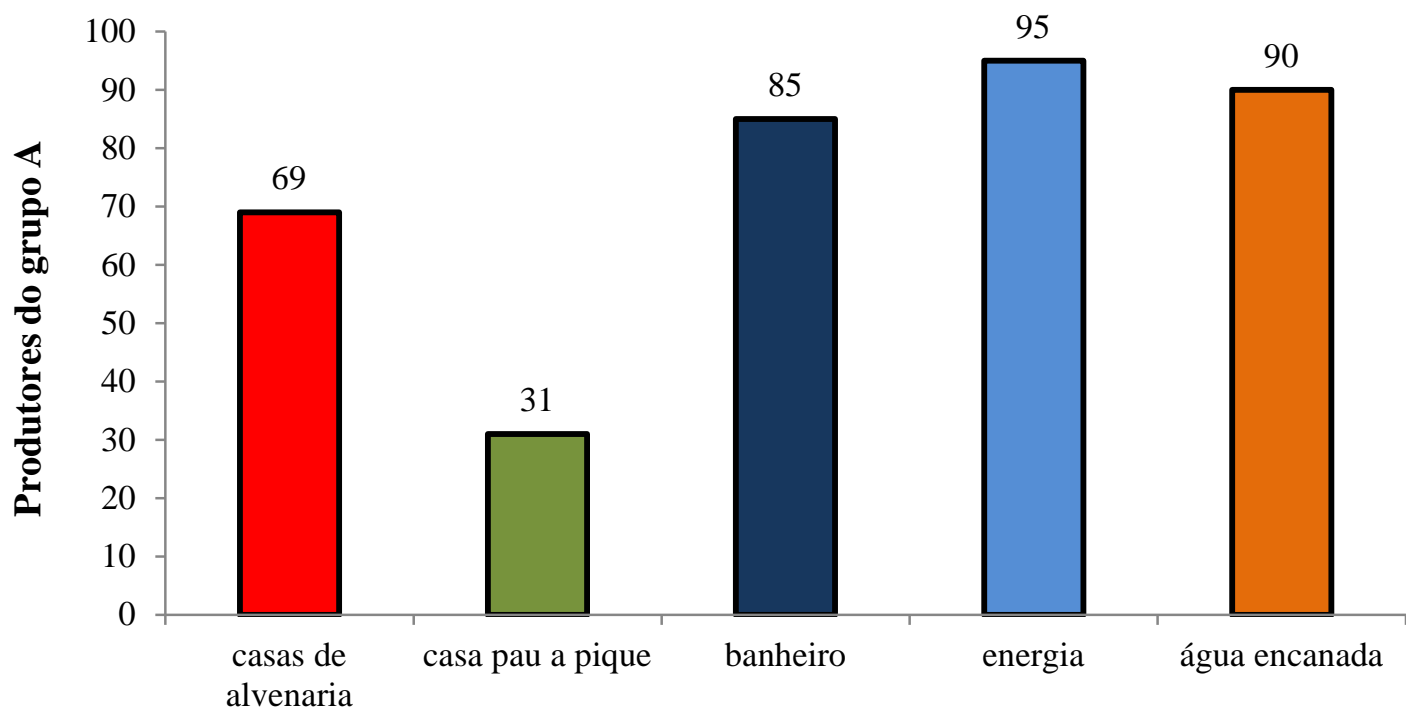

Condições de vida

Figura 2. Condições de vida dos produtores do grupo A. Crato-CE.

Nesse grupo, onde em média cada produtor possui 12 hectares, a tecnologia mais aplicada é a aração, seguida pelo uso de defensivos agrícolas (Tabela 1). Percebeu-se a necessidade de um incentivo pelos órgãos competentes, através de assistência técnica, cursos, palestras e subsídios para que essa realidade possa ser melhorada.

Tabela 1. Diagnóstico tecnológico das propriedades do grupo A. Crato-CE.

\begin{tabular}{ll}
\hline Tecnologia empregada & $\%$ \\
\hline Aração & 72 \\
Defensivos agrícolas & 54 \\
Adubação & 31 \\
Análise de solo & 10 \\
Irrigação & 10 \\
Compra de sementes (feiras) & 13 \\
\hline
\end{tabular}

FONTE: Dados da pesquisa 
SILVA et al.(2008) afirmaram que quando o solo não tem capacidade de suprir as quantidades de nutrientes exigidas pelas plantas e houver retorno econômico, a prática da adubação deve ser empregada e a forma mais rápida e econômica para avaliar a disponibilidade de nutrientes no solo e determinar a quantidade de fertilizantes a ser empregada é a análise do solo.

No que se refere à comercialização da produção (Figura 3), observou-se que $90 \%$ dos produtores rurais comercializam sua produção em feiras, intermediários ou em ambos.

ప్ర

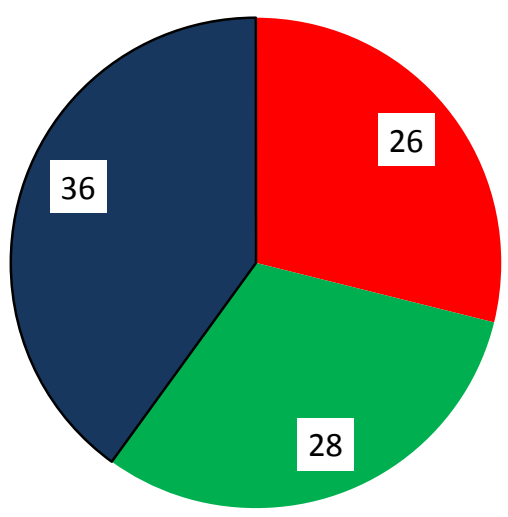

- Feiras

- Intermediários

$\square$ Feiras + Intermediários

Figura 3. Comercialização da produção do grupo A. Crato-CE. 
Verifica-se que $36 \%$ fazem a comercialização de seus produtos tanto nas feiras como com intermediários e $26 \%$ o fazem somente com intermediários. Isso só reforça um dos grandes problemas atuais da agropecuária brasileira no que se refere ao modo como, principalmente, os pequenos produtores, negociam suas produções. $O$ fato de não possuírem um elo forte e direto com o consumidor os tornam dependentes de comerciantes com conhecimento de mercado e que ficam com a maior parte da renda obtida das vendas. É preciso que o agente atravessador seja excluído dos canais de comercialização de produtos agrícolas, pois só assim, o produtor se sentirá mais motivado a continuar na atividade camponesa, tão demandada por mão-de-obra rural e tal fato deve também ser seriamente avaliado na região do Cariri cearense. $36 \%$ dos proprietários possuem créditos agrícolas com destaque para o PRONAF (Programa Nacional de Fortalecimento da Agricultura Familiar).

Quanto ao tipo de PRONAF utilizado, tem-se: 7\%; 18\%; 6\% e 5\% do A (os assentados pelo processo de reforma agrária), B (os com baixa produção e pouco potencial de aumento da produção), C (os com exploração intermediária, mas com bom potencial de resposta produtiva) e $\mathrm{F}$ (aquisição de máquinas, tratores e implementos agrícolas, veículos utilitários), respectivamente para o grupo $A$. Esse programa que se estendeu de forma considerável por todo o território nacional ampliou o montante financiado, desenvolveu programas especiais para atender diversas categorias, assumiu a assistência técnica e reforçou a infra-estrutura tanto dos próprios agricultores como dos municípios em que se encontram (GUANZIROLI, 2008).

O grupo B corresponde ao restante das propriedades avaliadas (37\%), onde se cultiva apenas a agricultura de subsistência: consórcio milho e feijão (26,3 ha), milho e fava (21,2 ha). As condições de moradia, desse são inferiores ao grupo A (Figura 4). Essa realidade reflete a característica dessa agricultura, já que uma boa parte do que produz é utilizada para seu sustento e não há diversidade de cultivo como observada no primeiro grupo.

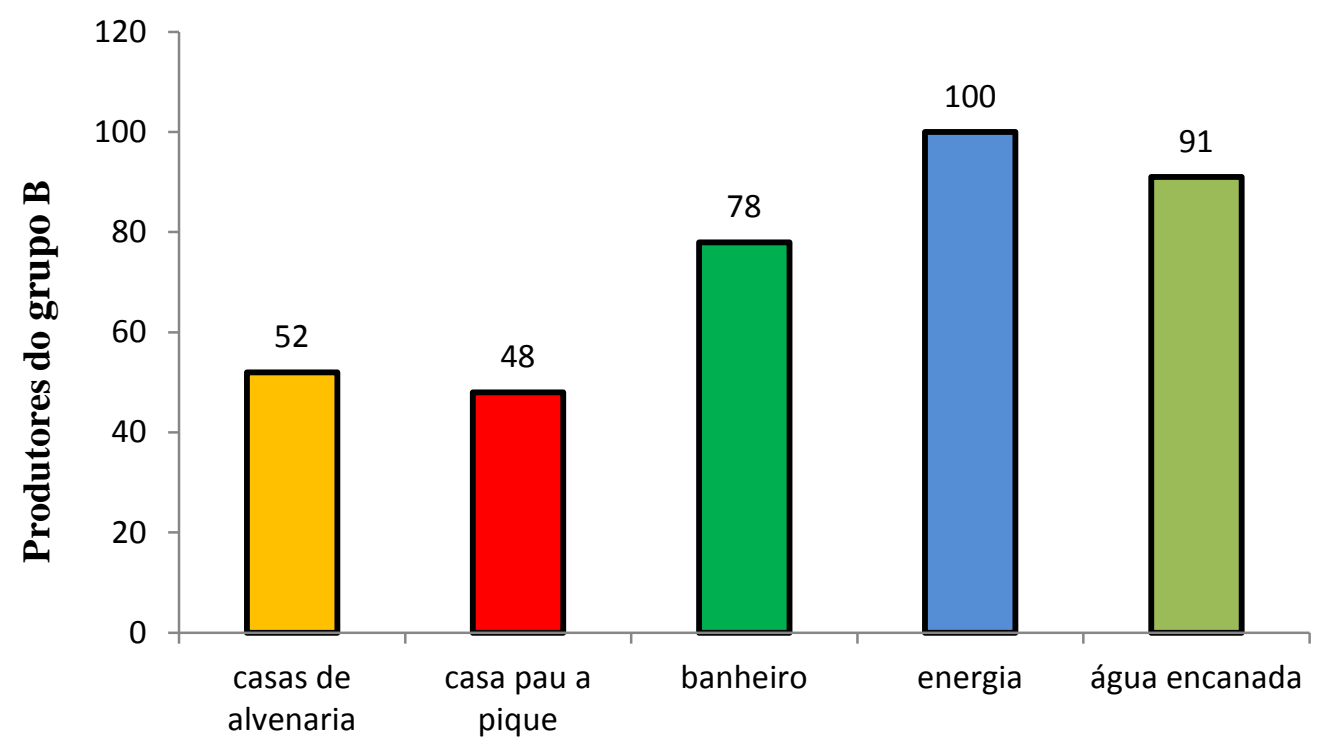

Condições de vida

Figura 4. Condições de vida dos produtores do grupo B. Crato-CE. 
Os produtores do grupo B possuem em média três hectares, cujas sementes são adquiridas geralmente através da Empresa de Assistência Técnica e Extensão Rural do Ceará (EMATER-CE). Há uma centralização na tecnologia empregada, aração e defensivos agrícolas, em detrimento das restantes (Tabela 2). A agricultura de subsistência, em geral de natureza familiar, é bem menos tecnificada, conta com poucas possibilidades do emprego de tecnologias mais avançadas, resultando em produtividade, em geral, sensivelmente mais baixa (PATERNIANI, 2001).

Tabela 2. Diagnóstico tecnológico das propriedades do grupo B. Crato-CE.

\begin{tabular}{lc}
\hline Tecnologia empregada & $\%$ \\
\hline Aração & 52 \\
Defensivos agrícolas & 43 \\
Adubação & 0 \\
Análise de solo & 0 \\
Irrigação & 0 \\
Compra de sementes & 13 \\
\hline
\end{tabular}

Fonte: elaborada pelo autor

$\mathrm{Na}$ Figura 5, observa-se que a maioria dos produtores (65\%)comercializa o excedente de sua produção, demonstrando que,além de desenvolver a produção de alimentos para subsistência,os mesmos têm interesse em obter uma renda adicional. Também se percebe um predomínio de comercialização dos produtos para intermediários. Este resultado é relevante, pois maior retorno econômico poderia ser obtido se os produtores vendessem seus produtos diretamente ao consumidor de uma forma organizada e orientada pelas associações locais.Almeida \& Navarro (1998), mencionam que há de se ter políticas que garantam preços compatíveis e estáveis como fatores importantes para a manutenção das unidades familiares que dependem exclusivamente da terra e da mão-de-obra familiar.

Outra informação é que $35 \%$ do total de proprietários possuem créditos agrícolas PRONAF C(os com exploração intermediária, mas com bom potencial de resposta produtiva). 


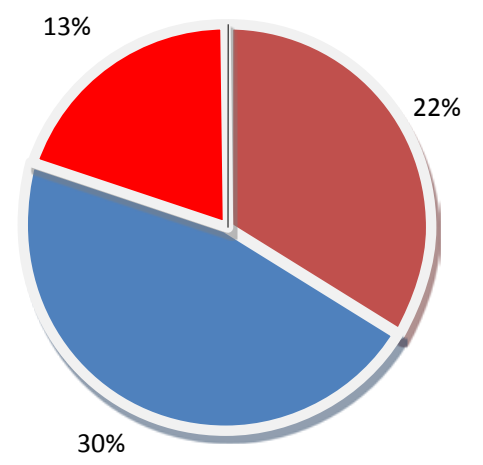

$\square$ feiras $\square$ intermediários $\square$ feiras e intermediários

Figura 5. Porcentagem de produtores do grupo B que comercializam o excedente da produção. Crato-CE.

Em Barbalha, as cinqüenta e quatro propriedades visitadas foram classificadas em três grupos: A, B e C, seguindo o raciocínio de Buainain(2007) que cita que a agricultura é um universo profundamente heterogêneo, seja em termos de disponibilidade de recursos, acesso ao mercado, capacidade de geração e acumulação de renda.

O grupo A corresponde a agricultura de subsistência e fruticultura é representado por $22 \%$ das propriedades, merecendo destaque o consórcio do milho e feijão com 28,6 ha de área plantada e o cultivo de goiaba e banana, com 16,1 e 15,8 ha, respectivamente.

O grupo B que correspondeu à agricultura de subsistência (milho, feijão, fava, soja, mandioca, macaxeira, arroz e andu), constitui $54 \%$ das propriedades analisadas, com destaque para o consórcio milho e feijão (em torno de 28,1 ha) que equivale aproximadamente a $41 \%$ da área total cultivada (Figura 6).

Esse dado está de acordo com Furtado et al.(2002) onde se observa o predomínio do cultivo em consórcio, principalmente com milho e feijão, que ocorre na agricultura de subsistência. O cultivo hortaliças (grupo C), localizado no distrito de Arajara, representa $24 \%$ das propriedades amostradas. Merece destaque o cultivo do coentro $(2,35 \mathrm{ha})$ e a alface $(1,6$ ha). 


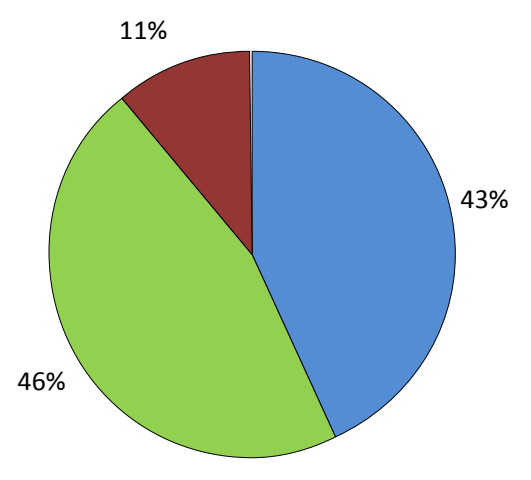

A: milho, feijão e banana $\square$ B;milho, feijão, fava e arroz

C: coentro, pimentão e cebolinha

Figura 6.Percentagem de áreas cultivadas nos grupos A, B e C. Barbalha-CE.

Em relação às condições de vida no município de Barbalha, verifica-se que o grupo $B$ tem menor índice de residências construídas em alvenaria, no entanto todas as propriedades têm energia elétrica, com destaque para o grupo $C$, representado pelo cultivo de hortaliças como o que apresentou os melhores resultados (Tabela 3 ).

Tabela 3. Condições de vida dos grupos $A, B$, e C, em percentagem. Barbalha-CE.

\begin{tabular}{cccccc}
\hline Grupo & Alvenaria & Pau a pique & Banheiro & Energia elétrica & Água encanada \\
\hline A & 100 & 0 & 92 & 100 & 83 \\
B & 93 & 7 & 97 & 100 & 97 \\
C & 100 & 0 & 100 & 100 & 100
\end{tabular}

Grupos A: subsistência e fruticultura B: subsistência C: hortaliças

Na Tabela 4, observa-se que o grupo B não utiliza irrigação e que o grupo $C$ apesar de não utilizar a aração e análise de solo, é o que mais utiliza integralmente as tecnologias de irrigação, compra de sementes e adubação, gerando assim um aumento no índice de capacitação do produtor. O desejável é que o restante dos grupos, com o tempo, galgar um patamar mais alto, que os aproxime de uma agricultura de elevada tecnologia, podendo, eventualmente, chegar a uma agricultura nos moldes empresariais. 
Tabela 4. Tecnologia utilizada nos grupos em percentagem. Barbalha-CE.

\begin{tabular}{ccccccc}
\hline Grupo & Aração & Irrigação & Defensivo & $\begin{array}{c}\text { Compra de } \\
\text { sementes }\end{array}$ & Adubação & Análise de solo \\
\hline A & 67 & 58 & 50 & 17 & 67 & 42 \\
B & 58 & 0 & 31 & 21 & 0 & 0 \\
C & 0 & 100 & 8 & 100 & 100 & 0 \\
\hline
\end{tabular}

Grupos A: subsistência e fruticultura $\quad$ B: subsistência C: hortaliças

Em relação à comercialização da produção, o grupo $A$ com 12 produtores e $C$ com 13 tem $67 \%$ e $100 \%$ dos produtores que realizam essa atividade, já o grupo B com 29 produtores, apenas $49 \%$ destes comercializam o excedente de sua produção. (Tabela 5).

Tabela. 5. Comercialização da produção nos grupos A, B e C, em \%. Barbalha-CE.

\begin{tabular}{cccc}
\hline Grupo & Feiras & Intermediários & Feiras e Intermediários \\
\hline A & 42 & 17 & 8 \\
B & 14 & 21 & 14 \\
C & 100 & 0 & 0 \\
\hline
\end{tabular}

Grupos A: subsistência e fruticultura B: subsistência C: hortaliças

Percebe-se

que os

agricultores que produzem frutas ou hortaliças tendem a ter melhores noções ou condições comerciais para negociarem suas produções diretamente com os consumidores, especificamente, nas feiras livres, ao contrário do que ocorre com os agricultores com lavouras destinadas à produção somente de itens de subsistência, onde preferem ou necessitam de outras pessoas para negociarem a produção obtida e muitos excedentes de sua lavoura.

Em relação à pesquisa no município de Missão Velha, foram visitadas cinqüenta e três propriedades rurais que podem classificadas em dois grupos A e B (Figura 7). O grupo A trabalha com a agricultura de subsistência e fruticultura. Destacando-se o consórcio do milho com o feijão (23 ha) e o cultivo de banana (31 ha). O grupo B corresponde a $62 \%$ das propriedades analisadas, cuja agricultura é de subsistência, merecendo maior destaque em termos de área a cultura do milho (34,5 ha) e o consórcio do milho com o feijão (33 ha). 


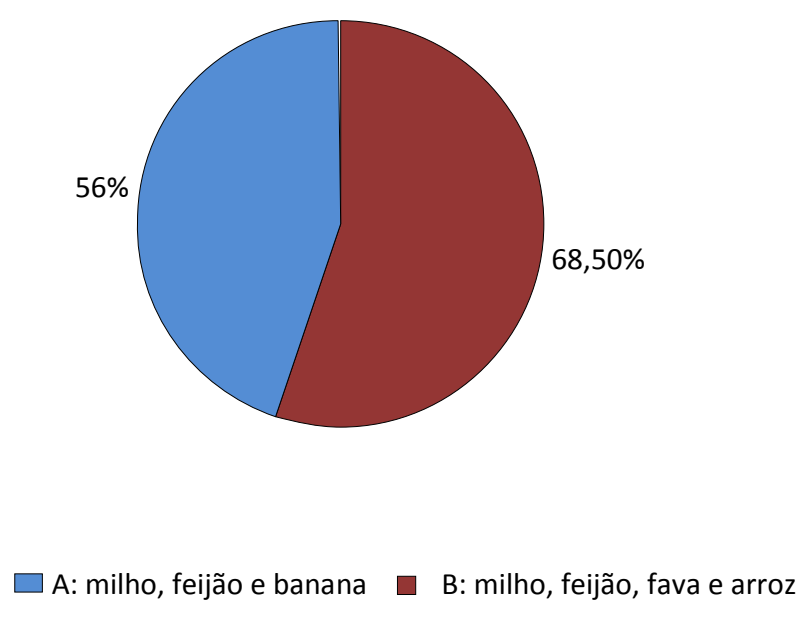

Figura 7. Percentagem da produção (ha) nos grupos A e B.Missão Velha-CE.

Quanto às condições de vida, percebe-se no grupo A que a diversificação na produção, permite um fluxo contínuo desta, que repercute na renda do produtor e por conseqüência na sua condição de vida. (Tabela 6).

Tabela 6. Condições de vida dos grupos em percentagem. Missão Velha-CE.

\begin{tabular}{cccccc}
\hline Grupo & Alvenaria & Pau a pique & Banheiro & Energia elétrica & Água encanada \\
A & 100 & 0 & 100 & 100 & 100 \\
B & 73 & 27 & 97 & 100 & 82 \\
\hline
\end{tabular}

Grupo A: subsistência e fruticultura Grupo B: subsistência

Na Tabela 7, verifica-se que nomunicípio de Missão Velha que o grupo $B$ não utiliza irrigação nem adubação, o que o diferencia do grupo $A$.

Tabela 7. Tecnologia utilizada nos grupos em percentagem. Missão Velha-CE.

\begin{tabular}{ccccccc}
\hline Grupo & Aração & Irrigação & Defensivos & $\begin{array}{c}\text { Compra de } \\
\text { semente }\end{array}$ & Adubação & Análise de solo \\
A & 90 & 100 & 80 & 10 & 100 & 0 \\
B & 67 & 0 & 76 & 15 & 0 & 0 \\
\hline
\end{tabular}

Grupo A: subsistência e fruticultura e Grupo B: subsistência

A comercialização nestes grupos ocorre da seguinte forma: o grupo A com vinte produtores tem $80 \%$ dos produtores que comercializam sua produção, já o grupo B com trinta 
e três produtores, apenas $24 \%$ dos proprietários comercializam apenas o excedente de sua produção. (Tabela 8).

Tabela 8. Comercialização nos grupos A e B em percentagem. Missão Velha-CE.

\begin{tabular}{cccc}
\hline Grupo & Feiras & Intermediários & Feiras e Intermediários \\
\hline A & 0 & 80 & 0 \\
\hline B & 0 & 21 & 3 \\
\hline
\end{tabular}

Grupos A: subsistência efruticultura B: subsistência

Ao contrário do que se verifica em Barbalha, os produtores do município de Missão Velha entregam a parte produzida destinada à venda quase que somente à agentes intermediários, demonstrando uma característica negativa para o setor agropecuário local. Tal fato revela-se como uma necessidade quando se tem ou se quer como objetivo o desenvolvimento econômico de uma cidade e o atendimento da demanda por alimentos dessa natureza. Ações de capacitação e execução de políticas agrícolas que incentivem a oferta de alimentos o mais próximo possível do consumidor devem ser constantemente focadas e discutidas nas instituições envolvidas, de naturezas pública e privada.

\section{CONCLUSÕES}

A agricultura nos municípios analisados é voltada para a agricultura de subsistência, sendo que a maioria das propriedades cultiva o consórcio de milho e feijão ou milho e fava. Em relação às condições de vida,estas são consideradas boas já que a maioria dos produtores reside em casas de alvenaria, beneficiados com água encanada, energia elétrica e banheiro.Porém verifica-se que ainda há pouca utilização de tecnologia.Um índice favorável para os municípios pode ser percebido pelo fato que a maioria dos produtores comercializa seus produtos. Os resultados obtidos com este trabalho fornecem informações básicas para que os órgãos competentes planejem atividades de assistência técnica, cursos sobre gerenciamento agrícola e organização de produtores e dessa forma contribuirá para melhoria da agricultura praticada nessas propriedades.

\section{Agradecimentos}

A Fundação Cearense de Apoio ao Desenvolvimento Científico e Tecnológico (FUNCAP) pela bolsa concedida e a Empresa de Assistência Técnica e Extensão Rural do Ceará (EMATERCECARIRI) pelo auxílio na pesquisa. 


\section{REFERÊNCIAS BIBLIOGRÁFICASGlaydson, favor ordenar!}

1. ALMEIDA, J.; NAVARRO, Z. (Org.) Reconstruindo a agricultura:idéias e ideais na perspectiva de um desenvolvimento rural/sustentável. 2 ed. Porto Alegre: UFRGS, 1998. 323 p.

2. ALTIERI, Miguel. Agroecologia: A dinâmica produtiva da agricultura sustentável. Porto Alegre: Ed. Da Universidade/UFRGS, 2001.

3.ALVES, E. J. A cultura da banana: aspectos técnicos, socioeconômicos e agroindústrias. 2. ed. Brasília: Embrapa, 1999. 585 p.

4. BUAINAIN, A.M.; ROMEIRO, A.R; GUANZIROLI, C. Economia e Sociologia Rurale o novo mundo rural. Sociologias.Rev. Econ. Sociol. Rural, Brasília, v.45, n.2, 2007.

5. CAETANO, L.C.S.; FERREIRA, J.M.; ARAÚJO, M.L. de. Produtividade de cenoura e alface em sistema de consorciação. Horticultura Brasileira, Brasília, v.17, n.2, p.143-146,1999.

6. CERETTA, C.A. Sistema de cultivo de mandioca em fileiras simples e duplas em monocultivo e consorciadas com girassol. Porto Alegre, 1986. 122p. Dissertação (Mestrado em Fitotecnia) - Universidade Federal do Rio Grande do Sul.

7. COELHO, F.C.; FREITAS, S. de P.; RODRIGUES, R. et al. Manejo de plantas daninhas e sistema de consórcio na cultura do quiabeiro: produtividade e qualidade de frutos. In: CONGRESSO BRASILEIRO DE OLERICULTURA, 40., 2000, São Pedro, Resumos..., Brasília: SOB/FCAV-UNESP, 2000. v.18, n.2, p.587-588.

8. FURTADO, M. R.; CRUZ, C. D.; CARDOSO, A. A. et al. Análise de trilha do rendimento do feijoeiro e seus componentes primários em monocultivo e em consórcio com a cultura do milho. Cienc. Rural, Mar./Apr. 2002, v.32, n.2, p.217-220. 
9. GUANZIROLI, C.E. PRONAF dez anos depois: resultados e perspectivas para o esenvolvimento rural.

Disponível

em: http://www.anpec.org.br/encontro2006/artigos/A06A169.pdf.

10. LIMA, Marcelo Bezerra et al . Efeitos das culturas de milho (Zea mays), feijão (Phaseolus vulgaris) e caupi (Vigna unguiculata) na agregação de valor ao cultivo da bananeira 'Terra', em Teolândia, litoral sul da Bahia. Revista Brasiléia de Fruticultura, Jaboticabal, v.27, n.1, abr. 2005.

11. MELO, F. de B.; CARDOSO, M.J.; , ANDRADE JÚNIOR, A.S.; QUEIROZ, V.R. Crescimento e produção de frutos de bananeira cultivar "Grand Naine" relacionados à adubação química. Revista Ciência Agronômica, v.37, n.2, p.246-249, 2006.

12. MOREIRA, R. S. Banana: teoria e prática de cultivo. 2. ed. Campinas: FundaçãoCargill, 1999. 167 p. 1 CD-ROM.

13. NUNES, H.V. et al. Influência de sistemas de culturas, mucuna preta e adubação mineral sobre a qualidade fisiológica de sementes de milho. Rev. bras. Sementes, Pelotas, v.28 n.3, 2006.

14. OLIVEIRA, C.V. et al. Diagnóstico e tipificação dos sistemas de produção praticados pelos pequenos produtores do município de Caraíbas-BA. Petrolina, PE. EMBRAPA SemiÁrido/Salvador: CAR, 1999. 66p. EMBRAPA Semi-Árido. Documento, 131.

15. OTANI, M.N. et al.As transformações no setor rural do município de Dourado, Estado de São Paulo, 1995/96-1999/2000.Informações Econômicas, SP, v.32, n.6, jun. 2002.

16. PATERNIANI, E. Agricultura sustentável nos trópicos.Estudos Avançados. 2001, v.15, n.43 p.303-326. 
17 REZENDE, B.L.A.; CANATO, G.H.D.; CECÍlIO FILHO, A.B. Produtividades das culturas de tomate e alface em função da época de estabelecimento do consórcio, em relação a seus monocultivos, no cultivo de inverno. In: CONGRESSO BRASILEIRO DE OLERICULTURA, 42.,Resumos..., Uberlândia. v.20, n.2, 2002b. 1 CD-ROM.

18. SILVA, Leandro Souza da et al. Avaliação de métodos para estimativa da disponibilidade de fósforo para arroz em solos de Várzea do Rio Grande do Sul.Revista Brasileira Ciência do Solo, 2008, v.32, n.1 p.207-216.

19. VIEIRA, C. O feijão em cultivos consorciados. Viçosa: UFV, 1989. 134p.

20. WILLEY, R.W. Intercropping: its importance and research needs. Part 1. Competition and yield advantages. Field CropAbstracts, Hurley, v.32, n.1, p.1-10, 1979. 